\title{
MOTIVATION OF MARATHON RUNNERS IN POLAND
}

\author{
JOANNA STARZAK'1, KRZYSZTOF SAS-NOWOSIELSKI² \\ ${ }^{1}$ Doctoral Studies, The Jerzy Kukuczka Academy of Physical Education in Katowice, \\ Faculty of Physical Education \\ 2Institute of Sport, The Jerzy Kukuczka Academy of Physical Education in Katowice, Faculty of \\ Physical Education, Department of Pedagogy and Psychology
}

\author{
Mailing address: Joanna Starzak, The Jerzy Kukuczka Academy of Physical Education in Katowice, \\ 72a Mikołowska Street, 40-065 Katowice, Poland, tel.: +48 32 2075128, \\ e-mail: j.starzak@awf.katowice.pl
}

\begin{abstract}
Introduction. In recent years, the growing number of marathon runners in the world has raised questions about the factors which motivate them. The main purpose of this study was to investigate the motivations of runners and to examine how sex, age, level of experience, and number of kilometers run per week affect motivation. Material and methods. Motivation was assessed in 240 subjects using a questionnaire (the Polish adaptation of the Motivations of Marathoners Scales), which was completed during the three biggest marathons held in Poland in 2016. Results. The results revealed that in general people taking part in marathon races were primarily motivated by health and well-being, women had greater endorsement of health and psychological motives, and younger runners were motivated by competition, personal goal achievement, and self-esteem. The importance of the last two motives decreased with experience. Personal goal achievement and life meaning were predictors of training volume. Surprisingly, weight concern was a predictor of lower weekly training mileage. Conclusions. The present findings indicated that particular motives differed between females and males and between younger and older participants. The research results are going to help to develop effective techniques to enhance exercise motivation, depending on age, sex, and training characteristics.
\end{abstract}

Key words: running, marathon, endurance training, motivation, sport psychology

\section{Introduction}

The popularity of marathon races has been rapidly increasing in recent years. Long-distance running has been transformed from a sport for elite endurance athletes into a recreational activity. According to the "Run Repeat" report, the worldwide growth in the popularity of marathon running between 2009 and 2014 was the greatest in the Russian Federation (300\%), China (259\%), and the Philippines (211\%), and in eighteen countries (including Poland), it amounted to more than 50\% [1]. These few statistics are a good illustration of the thesis that long distance running, including marathon races, is becoming increasingly popular. Without doubt, running is an inexpensive, easily accessible form of physical activity, which does not require any sophisticated equipment, but at the same time, running distances as long as $42.2 \mathrm{~km}$ is highly exhausting, painful, and sometimes even dangerous to health or life, especially when we consider the incidence of sudden cardiac deaths during some events $[2,3]$. This raises the question what makes this cumbersome activity so appealing to people who are not professional athletes.

Initially, motives for running marathons were studied with the use of open-ended response format questionnaires $[4,5,6]$ or interviews [7], which indeed did not restrict the participants' narrations, but at the same time, these data collection methods have not made it possible to explore some of their possible motives, especially those that are unconscious or are difficult to retrieve from memory, or to compare results between studies. For these reasons, a more psychometrically sound measure, the
Motivations of Marathoners Scales, was developed by Masters, Ogles, and Jolton [8]. The measure assesses the relative importance of nine groups of motives (general health orientation, weight concern, affiliation, competition, recognition, personal goal achievement, self-esteem, psychological coping, and life meaning) that are grouped into four broader categories: social, psychological, achievement, and physical health motives. Initial studies that used this measure demonstrated that social and competitive motives prevailed among more experienced marathoners, whereas personal achievement and health were more important for less experienced runners [9] and that obligatory runners were more likely to be driven by achievement and recognition, while recreational runners attached higher value to general health orientation [10]. The motives for running marathons also seem to be different for male and female runners, with the former ascribing greater importance to recognition/approval, competition, and goal achievement [11, 12]. In subsequent studies, other factors, like age [13], training status $[8,10,14,15,16]$, different distances (full marathons, ultramarathons, adventure races) [17], and even the fact of finishing the marathon or dropping out of the training before the competition [18], were taken into account. Representatives of other disciplines, such as swimming [19] or cycling [20], were also studied.

The aim of this study is the further exploration of the motives of marathon runners with regard to their demographic and training status (gender, age, training experience, and weekly training mileage). 


\section{Material and methods}

Data for the study were collected during race registration the day prior to the three biggest marathons held in Poland in 2016: the 15th PZU Cracovia Marathon, the 34th PKO Wrocław Marathon, and the 17th PKO Poznań Marathon. The study was approved by the Bioethics Committee for Scientific Research at the Academy of Physical Education in Katowice, Poland.

A total of 300 questionnaires were distributed, and 282 were returned (the response rate was 94\%), of which 240 were completely and correctly filled in. The final sample, then, was comprised of 144 males and 96 females aged from 20 to 70 years $($ mean $=35.45, \mathrm{SD}=9.62)$. The proportion of male and female respondents was similar to the one reported in the "National runners list report" [21] comprising 60,641 runners recruited via the Internet. About seven out of every ten subjects ran more than 30 kilometers per week, and over half of them (51\%) had at least three years of experience in marathon running.

The motivation of the runners was measured using the Motivation of Marathoners Scales (MOMS) [8] in its Polish adaptation [14]. The Polish version of the scale consists of 41 items assessing nine motives: general health orientation (e.g., "to improve my health"), weight concern (e.g., "to help control my weight"), affiliation (e.g., "to participate with my family or friends"), recognition/approval (e.g., "to earn the respect of people in general"), competition (e.g., "to get a faster time than my friends"), personal goal achievement (e.g., "to make my body perform better than before"), psychological coping (e.g., "to improve my mood"), self-esteem (e.g., "to feel proud of myself"), and life meaning (e.g., "to make my life more complete"). Each item is rated on a seven-point Likert scale from 1 ("not a reason") to 7 ("a most important reason"). All subscales were internally consistent, with Cronbach's alpha values ranging from 0.85 (for self-esteem) to 0.90 (for weight concern and recognition/approval).

In order to establish the demographic and training status of the participants, we also collected data concerning age, gender, the number of previously completed marathons, weekly mileage, and years of running experience. Participants were organized into four age groups, according to the following classifications commonly used during marathon races: $20-29$ ( $\mathrm{n}=75$, $31.25 \%), 30-39(\mathrm{n}=84,35.00 \%), 40-49(\mathrm{n}=64,26.67 \%)$, and $50+$ years $(\mathrm{n}=17,7.08 \%)$.

\section{Data analysis}

The software package Statistica 12 (STATSOFT) was used to examine the data and perform statistical tests. First, internal consistency, descriptive statistics, and bivariate correlations between variables were calculated. Secondly, we analyzed the relationships between variables and performed t-tests and linear regression analyses. Additionally, the magnitude of the relationships was assessed using Cohen's $d$.

\section{Results}

For the total sample, the primary motives for marathon running were general health orientation $($ mean $=5.17, \mathrm{SD}=1.32$ ) and psychological coping (mean $=4.70, \mathrm{SD}=1.55)$, while the least important ones were recognition/approval (mean $=2.98$, $\mathrm{SD}=1.46)$ and competition (mean $=3.10, \mathrm{SD}=1.57)$. In two categories of motives, differences could be observed between male and female runners - these were physical health and psychological coping. In the first category, female runners reported significantly stronger weight concern than males $($ mean $=4.38$ vs mean $=3.76, \mathrm{t}_{(238)}=2,81, \mathrm{p}=0.005, \mathrm{~d}=0.37$ ), while no significant effect of sex was found for the other motive in this category. In the case of psychological motives, all three motives were sexrelated, with female runners reporting the greater importance of psychological coping (mean $=4.99$ vs mean $=4.50, \mathrm{p}=0.017$, $\mathrm{d}=0.32$ ), self-esteem (mean $=5.05$ vs mean $=4.21, \mathrm{p}=0.001$, $\mathrm{d}=0.56)$, and life meaning (mean $=4.87$ vs mean $=4.20, \mathrm{p}=$ $0.02, d=0.43)$. See Table 1 for detailed information.

Linear regression was used to test if age significantly predicted participants' motives for running marathons. Four models were significant although the proportion of variance explained was quite small, not exceeding 6\%: general health orientation $\left(\mathrm{R}^{2}=0.02, \mathrm{~F}_{(1,238)}=4.57, \mathrm{p}=0.034\right)$, competition $\left(\mathrm{R}^{2}\right.$ $\left.=0.03, \mathrm{~F}_{(1,238)}=7.52, \mathrm{p}=0.007\right)$, personal goal achievement $\left(\mathrm{R}^{2}=\right.$ $\left.0.06, \mathrm{~F}_{(1,238)}=13.97, \mathrm{p}<0.001\right)$, and self-esteem $\left(\mathrm{R}^{2}=0.03, \mathrm{~F}_{(1,238)}\right.$ $=7.24, \mathrm{p}=0.008)$. As could be expected, the importance of the motive of health orientation increased slightly with advancing age $(\beta=0.14, t=2.14, p=0.034)$, while that of the remaining motives decreased with age (competition: $\beta=0.17, \mathrm{t}=-2.74, \mathrm{p}=$ 0.007; personal goal achievement: $\beta=0.24, \mathrm{t}=-3.74, \mathrm{p}<0.001$; self-esteem: $\beta=0.17, \mathrm{t}=-2.69, \mathrm{p}=0.008$ ).

Experience, expressed in the number of years of running, was related to the motives of personal goal achievement $\left(\mathrm{R}^{2}=\right.$ $\left.0.02, \mathrm{~F}_{(1,238)}=5.68, \mathrm{p}=0.018\right)$ and self-esteem $\left(\mathrm{R}^{2}=0.02, \mathrm{~F}_{(1,238)}\right.$ $=5.75, p=0.017)$. In both cases, the greater the running experience was, the less important the aforementioned motives were (personal goal achievement: $\beta=0.15, \mathrm{t}=-2.38, \mathrm{p}=0.018$; selfesteem: $\beta=0.15, t=-2.40, p=0.017$ ).

A comparison between runners affiliated to running clubs to those who were not affiliated with any institution revealed that they differed only in affiliation (mean $=4.95, \mathrm{SD}=1.63 \mathrm{vs}$ mean $=3.82, \mathrm{SD}=1.44 ; \mathrm{t}_{(238)}=3.61, \mathrm{p}<0.001$, Cohen's $\left.\mathrm{d}=0.73\right)$.

Motives for running marathons may also have an effect on an important training-related variable, namely on training volume. This hypothesis was researched with the use of stepwise regression analysis with motives as predictors of weekly training mileage. The model significantly explained 7 percent of variability in the dependent variable $\left(\mathrm{R}^{2}=0.07, \mathrm{~F}_{(4,235)}=4.09, \mathrm{p}=\right.$ $0.003)$. Three motives were found to be significant predictors of how many kilometers the participants ran a week: personal goal achievement $\left(\beta=0.14, \mathrm{t}_{(235)}=-2.03, \mathrm{p}=0.044\right)$, weight concern $\left(\beta=-0.17, \mathrm{t}_{(235)}=-2.60, \mathrm{p}=0.010\right)$, and life meaning $(\beta=0.18$, $\left.\mathrm{t}_{(235)}=-2.18, \mathrm{p}=0.030\right)$.

\section{Discussion}

The aim of the study was to investigate the motives of marathon runners in Poland with respect to their demographic and training status characteristics. The motives which were considered to be the most important were general health orientation, psychological coping, personal goal achievement, and self-esteem. All of them are, in a way, motives related to the participants' well-being - their physical and psychological health. The latter can be understood both as preventing mental health disturbances (psychological coping) and satisfying one's self-realization needs. In contrast, marathoners seem only to be marginally motivated by extrinsic motives such as the possibility of competing with others, comparing themselves to others, and gaining other people's approval.

In two categories of motives, differences between male and female runners were observed - these were physical health motives and psychological motives. In the first category, female runners were more concerned with their weight than the males. 
Table 1. Motives for marathon running for the whole sample and separately for male and female runners

\begin{tabular}{|c|c|c|c|c|}
\hline \multirow[b]{2}{*}{ Variable } & Total sample & Female & Male & \multirow[b]{2}{*}{ F/M differ. } \\
\hline & $\begin{array}{c}\text { Mean } \\
\text { (SD) }\end{array}$ & $\begin{array}{c}\text { Mean } \\
\text { (SD) }\end{array}$ & $\begin{array}{l}\text { Mean } \\
\text { (SD) }\end{array}$ & \\
\hline Physical health motives & $\begin{array}{c}4.65 \\
(1.26)\end{array}$ & $\begin{array}{c}4.87 \\
(1.24)\end{array}$ & $\begin{array}{c}4.50 \\
(1.25)\end{array}$ & $t_{(238)}=-2.23, p=0.026^{*}, d=0.30$ \\
\hline General health orientation & $\begin{array}{c}5.17 \\
(1.32)\end{array}$ & $\begin{array}{c}5.26 \\
(1.30)\end{array}$ & $\begin{array}{c}5.10 \\
(1.34)\end{array}$ & $t_{(238)}=-0.93, p=0.353, d=0.12$ \\
\hline Weight concern & $\begin{array}{c}4.00 \\
(1.70)\end{array}$ & $\begin{array}{c}4.38 \\
(1.71)\end{array}$ & $\begin{array}{c}3.76 \\
(1.66)\end{array}$ & $t_{(238)}=-2.81, p=0.005^{*}, d=0.37$ \\
\hline Psychological motives & $\begin{array}{c}4.57 \\
(1.37)\end{array}$ & $\begin{array}{c}4.97 \\
(1.27)\end{array}$ & $\begin{array}{c}4.31 \\
(1.37)\end{array}$ & $t_{(238)}=-3.77, p<0.001^{*}, d=0.50$ \\
\hline Psychological coping & $\begin{array}{c}4.70 \\
(1.55)\end{array}$ & $\begin{array}{c}4.99 \\
(1.51)\end{array}$ & $\begin{array}{c}4.50 \\
(1.54)\end{array}$ & $t_{(238)}=-2.41, p=0.017^{*}, d=0.32$ \\
\hline Self-esteem & $\begin{array}{c}4.55 \\
(1.56)\end{array}$ & $\begin{array}{c}5.05 \\
(1.42)\end{array}$ & $\begin{array}{c}4.21 \\
(1.57)\end{array}$ & $t_{(238)}=-4.19, p<0.001^{*}, d=0.56$ \\
\hline Life meaning & $\begin{array}{c}4.47 \\
(1.62)\end{array}$ & $\begin{array}{c}4.87 \\
(1.48)\end{array}$ & $\begin{array}{c}4.20 \\
(1.66)\end{array}$ & $t_{(238)}=-3.17, p=0.002^{*}, d=0.43$ \\
\hline Achievement motives & $\begin{array}{c}3.84 \\
(1.42)\end{array}$ & $\begin{array}{c}3.95 \\
(1.36)\end{array}$ & $\begin{array}{c}3.76 \\
(1.46)\end{array}$ & $t_{(238)}=-0.99, p=0.324, d=0.13$ \\
\hline Personal goal achievement & $\begin{array}{c}4.58 \\
(1.56)\end{array}$ & $\begin{array}{c}4.78 \\
(1.45)\end{array}$ & $\begin{array}{c}4.44 \\
(1.62)\end{array}$ & $t_{(238)}=-1.67, p=0.096, d=0.22$ \\
\hline Competition & $\begin{array}{c}3.10 \\
(1.57)\end{array}$ & $\begin{array}{c}3.11 \\
(1.52)\end{array}$ & $\begin{array}{c}3.09 \\
(1.61)\end{array}$ & $t_{(238)}=-0.13, p=0.893, d=0.13$ \\
\hline Social motives & $\begin{array}{c}3.51 \\
(1.27)\end{array}$ & $\begin{array}{c}3.70 \\
(1.21)\end{array}$ & $\begin{array}{c}3.38 \\
(1.30)\end{array}$ & $t_{(238)}=-1,91, p=0.058, d=0.25$ \\
\hline Affiliation & $\begin{array}{c}4.05 \\
(1.53)\end{array}$ & $\begin{array}{c}4.24 \\
(1.54)\end{array}$ & $\begin{array}{c}3.92 \\
(1.52)\end{array}$ & $t_{(238)}=-1.61, p=0.110, d=0.21$ \\
\hline Recognition/approval & $\begin{array}{c}2.98 \\
(1.46)\end{array}$ & $\begin{array}{c}3.16 \\
(1.40)\end{array}$ & $\begin{array}{c}2.85 \\
(1.49)\end{array}$ & $t_{(238)}=-1.63, p=0.104, d=0.21$ \\
\hline
\end{tabular}

In the second category, female runners reported stronger motives of psychological coping, self-esteem, and life meaning. These findings are consistent with previous research [10, 11, 16, 22 ] and - at least in the case of weight concern motives - the results could be associated with women's greater care for their appearance. The findings of previous research indicating that achievement motives are the most important among men $[10$, $12,16,21$ ] have not been confirmed.

Our study supports the findings of Ogles and Masters [13, 16], who found that older and younger runners endorse somewhat different reasons for running marathons. Younger runners endorsed the motives of personal goal achievement, competition, and increasing self-esteem more than older runners. In contrast, older runners reported the greater importance of the health orientation motive.

Our study also confirmed that another variable that is significantly related to some motives is running experience. In our study, it was related only to personal goal achievement and self-esteem, which were more important to less experienced runners. In contrast, Ruiz-Juan and Zarauz [15] found that the number of years of running experience was positively correlated to all psychological motives and negatively correlated with weight concern.

Some limitations of the current study should be mentioned. First of all, the sampling was based on a convenience protocol, and therefore the sample was not fully representative of the population of marathon runners. Secondly, due to the use of self-reporting, the answers given by participants may be biased.

\section{Conclusions}

The findings of the current study indicate that, in general, people taking part in marathon races are primarily motivated by health and well-being and only to a small extent by the need to be recognized and to realize themselves in competing with others. However, particular motives differ between females and males and between younger and older participants.

\section{Literature}

1. Run Repeat. (2014). Research, Marathon Performance Across Nations. Retrieved August, 12, 2017, from http:// runrepeat.com/research-marathon-performance-acrossnations.

2. Kim J.H., Malhotra R., Chiampas G., D’hemecourt P., Troyanos C., Cianca J. et al. (2012). Cardiac arrest during longdistance running races. The New England Journal of Medicine 366(2), 130-40. DOI: 10.1056/NEJMoall06468.

3. James J., Merghani A., Sharma S. (2013). Sudden death in marathon runners. Cardiac Electrophysiology Clinics 5(1), 43-51. DOI: 10.1016/j.ccep.2013.01.003.

4. Curtis J., McTeer W. (1981). The motivation for running. Canadian Runner, January, 18-19.

5. Summers J.J., Sargent G.I., Levey A.J., Murray K.D. (1982). Middle-aged, non-elite marathon runners: A profile. Perceptual $\mathcal{E}$ Motor Skills 54(3), 963-969. DOI: 10.2466/ pms.1982.54.3.963. 
6. Summers J.J., Machin V.J., Sargent G.I. (1983). Psychosocial factors related to marathon running. Journal of Sport Psychology 5, 314-331.

7. Barrell G., Chamberlain, A., Evans J., Holt, T., Mackean, J. (1989). Ideology and commitment in family life: A case study of runners. Leisure Studies 8(3), 249-262. DOI: $10.1080 / 02614368900390261$.

8. Masters K.S., Ogles B.M., Jolton J.A. (1993). The development of an instrument to measure motivation for marathon running: The Motivations of Marathoners Scales (MOMS). Research Quarterly in Exercise and Sport 64, 134-143. DOI: 10.1080/02701367.1993.10608790.

9. Masters K.S., Ogles B.M. (1995). An investigation of the different motivations of marathon runners with varying degrees of experience. Journal of Sport Behavior 18(1), 169-179.

10. Ogles B.M., Masters K.S., Richardson S.A. (1995). Obligatory running and gender: An analysis of participative motives and training habits. International Journal of Sport Psychology 26(2), 233-248.

11. Ruiz-Juan F., Zarauz A. (2011). Validation of the Spanish version of the Motivations of Marathoners Scales (MOMS). Revista Latinoamericana de Psicología 43(1), 139-156. [in Spanish]

12. Deaner R.O., Lowen A., Rogers W., Saksa E. (2015). Does the sex difference in competitiveness decrease in selective sub-populations? A test with intercollegiate distance runners. PeerJ 3, e884. DOI: 10.7717/peerj.884.

13. Ogles B.M., Masters K.S. (2000). Older vs. younger adult male marathon runners: Participative motives and training habits. Journal of Sport Behavior 23(2), 130-143.

14. Dybała M. (2013). The Polish adaptation of the Motives of Runners for Running Questionnaire. Rozprawy Naukowe AWF we Wrocławiu 40, 118-128.
15. Ruiz-Juan F., Zarauz A. (2014). Analysis of motivation amongst Spanish marathon runners. Revista Latinoamericana de Psicología, 46(1), 1-11. DOI: 10.1016/S01200534(14)70001-9. [in Spanish]

16. Ogles B.M., Masters K.S. (2003). A typology of marathon runners based on cluster analysis of motivations. Journal of Sport Behavior 26(1), 69-85.

17. Doppelmayr M., Molkenthin A. (2004). Motivation of participants in adventure ultramarathons compared to other foot races. Biology of Sport 21(4), 319-323.

18. Havenar J., Lochbaum M. (2007). Differences in participation motives of first-time marathon finishers and pre-race dropouts. Journal of Sport Behavior 30(3), 270-279.

19. Polatidou G., Batsiou S., Polatidou P. (2014). The Motivations of Marathoners Scales - MOMS: Evaluation of motives for Greek swimmers with disabilities. Proceedings of the Annual South-East European Doctoral Student Conference, issue 2014, 613-629.

20. LaChausse R.G. (2006). Motives of competitive and noncompetitive cyclists. Journal of Sport Behavior 29(4), 304314.

21. National runners list report. (2014). Retrieved June, 12, 2017 from http://www.polskabiega.sport.pl/pdf/nsb_raport.pdf. [in Polish]

22. Krouse R., Ransdell L., Lucas S., Pritchard M. (2011). Motivation, goal orientation, coaching, and training habits of women ultrarunners. Journal of Strength and Conditioning Research 25(10), 2835-2842. DOI: 10.1519/JSC.0b013e318204caa0.

Submitted: April 16, 2019

Accepted: December 13, 2019 